\title{
Questões sobre a identidade do jornalista contemporâneo'
}

\author{
Virginia Pradelina da Silveira Fonseca
}

Resumo

Neste artigo levantam-se pontos que possam contribuir para a reflexão sobre as implicações do aprofundamento da lógica flexível da etapa atual do capitalismo e da aplicação das novas tecnologias de comunicação e informação sobre a identidade dos jornalistas que atuam em grandes organizações de mídia. Com isso, procura-se inferir a forma como esse grupo profissional percebe a função do jornalismo como prática social. Inicia-se fazendo uma reconstituição do ambiente macro-estrutural da transição do século XX para o século XXI para, a seguir, passar-se à reflexão sobre as mudanças que se operam nas organizações jornalísticas. Por fim, discutem-se conceitos e questões relativas à identidade do jornalista contemporâneo.

Palauras-chave:

Jornalismo, Jornalistas, Identidade, Comunicação

\section{Some questions about the contemporary journalist identity}

\section{Sobre a autora}

Doutora em Comunicação e Informação, professora nos cursos de graduação e pós-graduação em Comunicação e Informação da Universidade Federal do Rio Grande do Sul. Em estágio pós-doutoral no Centro de Pesquisa

e Documentação de História Contemporânea do Brasil (CPDOC) da Fundação Getúlio Vargas. vpradelina@uol.com.br

\section{Abstract}

This article aims at raising some points which may contribute to a reflection on the implications of the deepening of the flexible logic of capitalism current stage and the application of communication and information new technologies on the identity of journalists who work in the major media organizations. Thus, it tries to infer the way this professional category perceives the purpose of journalism as a social practice. The article starts from a reconstitution of the macro-structural environment in which the transition from the XX century to the XXI century took place. After that, it presents some reflection on the changes that happened in the media organizations. Finally, it brings up concepts and questions related to the identity of the contemporary journalist.

Keywords:

Journalism, Journalists, Identity, Communication 
Este texto parte da seguinte indagação geral: de que forma as transformações na organização jornalística (empresa) modificam o jornalismo como instituição social? Como se delineiam as novas funções sociais dos jornalistas no tempo atual? De que forma a reorganização tecnoprodutiva se manifesta na constituição do ethos ${ }^{2}$ profissional $^{3}$ ? Em busca de respostas a esse tipo de questões, persegue-se, neste paper, o objetivo de levantar pontos que possam contribuir para a reflexão sobre as implicações do aprofundamento da racionalidade capitalista e da aplicação das novas tecnologias de comunicação e informação nas organizações de mídia sobre a identidade dos jornalistas - de forma a inferir como esse grupo profissional percebe a função do jornalismo como prática social.

Para isso, começa-se situando a discussão no ambiente macroestrutural da transição do século XX para o século XXI, tomando-se como eixo de reflexão a reestruturação global do capitalismo e o desenvolvimento das novas tecnologias de comunicação e informação. A partir da compreensão desse cenário, passa-se à reflexão sobre as mudanças que se operam nas organizações jornalísticas para, por fim, discutir conceitos e questões relativas à identidade do jornalista contemporâneo.

A perspectiva de análise circunscreve-se ao paradigma crítico das Ciências Sociais.

\section{A transição para o século XXI}

Um intenso processo de mudanças caracteriza as últimas décadas do século passado, especialmente a partir dos anos 1990, em decorrência da articulação de dois fatores de alcance mundial: a reorganização do capitalismo e a emergência das novas tecnologias de comunicação e informação. Pela profundidade e impacto sobre a vida de nações e sociedades, a estrutura social que emerge do processo chama a atenção de investigadores sociais das mais diversas tradições teóricas e recebe as mais distintas nomeações.

Weberiano, Castells (2000a) vê esse período como uma revolução, no sentido de intervalo na história, pontuada por eventos importantes que ocorrem com rapidez e ajudam a estabelecer a próxima era estável. Para o autor, a articulação entre novas tecnologias e capitalismo dá origem a uma nova estrutura social no século XXI: a "sociedade em rede" - global, capitalista, informacional. E sustenta que a disponibilidade de novas tecnologias, constituídas como um sistema na década de 1970, é que serviu de base para a reestruturação socioeconômica dos anos 1980. Em contrapartida, a utilização dessas tecnologias na década de 1980 teria condicionado em grande parte seus usos e trajetórias na década de 1990.

Marxista, Harvey (2001) também vê algum tipo de relação entre a ascensão de formas culturais pós-modernas, a emergência de modos mais flexíveis de acumulação do capital e um novo ciclo de

${ }^{1}$ Este texto foi submetido, originalmente, ao Grupo Temático Estúdios sobre Periodismo do IX Congresso da Asociación Latinoamericana de Investigadores de la Comunicación (ALAIC), México, 2008.

${ }^{2}$ A expressão aqui é entendida como a consciência atuante e objetiva de um grupo social, onde se manifesta a compreensão histórica do sentido da existência. Instância de regulação das identidades individuais e coletivas: as normas, os atos práticos que o homem repetidamente executa e por isso com eles se acostuma (Sodré, 2006: 24).

${ }^{3}$ Estas questões fazem parte o projeto de pesquisa "Capitalismo e tecnologias no jornalismo contemporâneo: funções sociais e práticas profissionais", em desenvolvimento como atividade de pós-doutorado no CPDOC/FGV, sob a supervisão da Profa. Dra. Alzira Alves de Abreu. 
"compressão do tempo-espaço" na organização do capitalismo, o que é facilitado pelas novas tecnologias. Fala em novo regime de acumulação ${ }^{4}$ - flexível, pós-fordista - para se referir ao mesmo processo.

A literatura sobre o tema nos apresenta ainda outras nomeações, como pós-industrialismo (Daniel Bell), pós-modernismo (Fredric Jameson), capitalismo tardio (Ernest Mandel), sociedade da informação e do conhecimento, sociedade das mídias, sociedade eletrônica ou high-tech, entre outras - ou simplesmente globalização, expressão corrente no senso comum ${ }^{5}$ que tanto pode ser interpretada como o triunfo final do capitalismo (Francis Fukuyama) ou como o apogeu da sua etapa monopólica.

A reestruturação capitalista a que se referem os autores, entretanto, independentemente de sua nomeação, constitui a reação do capital internacional à crise dos anos 1970, representada pela superacumulação ${ }^{6}$, pela ruptura do Acordo de Bretton Woods ${ }^{7}$, pela escassez de petróleo e pela elevação dos preços. Do ponto de vista político, compõe a crise do Estado do Bem-Estar Social (Harvey, 2001).

Neste texto, o fenômeno é entendido como a reestruturação da vida social sob a hegemonia da ordem capitalista, representando, assim, o início de um novo ciclo dentro da etapa monopólica que se institui com o suporte das novas tecnologias de comunicação e informação, que, por sua vez, sustentam a estruturação da nova forma de organização da produção.

Nesse cenário em que a informação adquire importância capital, os conglomerados de mídia passam a ser agentes econômicos estratégicos para a consolidação do novo regime de acumulação. Do ponto de vista político, veiculam um discurso legitimador da concepção de mundo hegemônica - de enaltecimento das virtudes do mercado. Da perspectiva econômica, constituem um dos setores de atração do capital transnacional. Empresas de capital nacional que tradicionalmente atuavam nas fronteiras do Estado-Nação são levadas a empreender mudanças profundas - na sua composição acionária, nas suas estruturas organizacionais e em seus métodos de gestão.

A necessidade de atrair grande volume de capitais para fazer frente aos vultosos investimentos em empreendimentos que precisam vislumbrar um mercado global acaba por transformar o próprio perfil das organizações. Para se adaptar à racionalidade requerida pelo ciclo flexível do capitalismo mundial, as empresas tendem às fusões, às associações e às várias outras formas de acordo corporativo. Os investimentos têm origem em distintos "lugares" - na chamada nova economia ${ }^{8}$, no mercado financeiro, na indústria automobilística, na indústria farmacêutica, de pneus, ou de qualquer outro setor interessado na ampliação e diversificação de lucros e no compartilhamento de riscos.

${ }^{4}$ Estabilização por um longo período da alocação do produto líquido entre consumo e acumulação. No século $\mathrm{XX}$, as economias capitalistas teriam experimentado dois tipos de regime de acumulação: o fordismo-keynesiano, politicamente expresso pelo Estado do Bem-Estar Social, e o regime de acumulação flexível, expresso pela retomada do liberalismo (Harvey 2001).

${ }^{5}$ Que se refere ao mesmo processo também como neoliberalismo.

${ }^{6}$ Superacumulação: condição em que podem existir ao mesmo tempo capital ocioso e trabalho ocioso, sem nenhum modo de se unirem como recursos para a consecução de tarefas socialmente úteis. Em outras palavras, grande capacidade produtiva ociosa, excesso de mercadorias e de estoques, excedente de capital-dinheiro e elevados índices de desemprego (Harvey, op. cit.: 170).

${ }^{7} \mathrm{O}$ acordo de Bretton Woods fora celebrado em $1944 \mathrm{e}$ instituía a conversibilidade fixa dos dólares americanos em ouro. Com isso, a moeda norte-americana tornou-se o meio do comércio mundial. Com a ruptura, nos anos 1970, as taxas de câmbio passaram a flutuar livremente (Harvey, op. cit., 2001).

${ }^{8}$ Segmento constituído por empresas de alta tecnologia. 
Como as novas tecnologias aceleram o tempo de giro do capital, todos os esforços direcionam-se para a conquista de um padrão de convergência tecnológica. Empresas tradicionalmente dedicadas à produção de conteúdos culturais para difusão em mídias específicas (jornais, revistas, rádio, televisão, cinema etc.) tendem a se transformar em conglomerados multimídia.

Em conseqüência, aprofunda-se a concentração de propriedade e de capital, provocando um novo turno na rodada de oligopolização e monopolização dos mercados dos produtos culturais.

No Brasil, o cenário é semelhante ao das economias avançadas, embora com as especificidades próprias a um país subdesenvolvido. No que respeita à regulação, toda a "rigidez" constitucional e infraconstitucional, tida como restritiva ao pleno desenvolvimento do capital, foi eliminada através de uma série de emendas à Constituição de 1988, aprovadas na segunda metade dos anos 1990. No período, foi quebrado o monopólio do Estado sobre as telecomunicações, abrindo caminho para a entrada de investimentos estrangeiros nas empresas, e leis específicas sobre televisão paga e telefonia móvel foram criadas para instituir novos padrões de regulação nas comunicações. Além disso, Emenda Constitucional aprovada em 2002 autorizou a participação em até 30\% de capital estrangeiro na composição acionária das empresas jornalísticas e de radiodifusão ${ }^{9}$.

Quanto à propriedade, as principais organizações de mídia no País continuam sob o controle de reduzido número de grupos familiares, políticos ou religiosos. Contudo, graças à flexibilidade inserida na Constituição, no início do novo século já se anunciavam as primeiras transações envolvendo grupos nacionais e empresas de capital transnacional: entre o Grupo Abril e o fundo de investimentos norte-americano Capital International Inc.; e o Grupo Folha e a Portugal Telecom, que no Brasil atua através da operadora de telefonia móvel Vivo. A concentração reflete-se na monopolização dos mercados, tanto em nível nacional (especialmente no caso das emissoras de radiodifusão) quanto regional.

Em pesquisa desenvolvida como parte da tese de doutorado defendida em 2005 junto ao Programa de Pós-Graduação em Comunicação e Informação da Universidade do Rio Grande do Sul, abordouse com maior amplitude e profundidade as formas de manifestação do capitalismo na sua etapa global, pós-fordista, nas organizações jornalísticas, com ênfase na reestruturação das empresas, do trabalho e da produção ${ }^{10}$. Deixou-se de analisar, entretanto, um aspecto relevante relacionado ao mesmo processo: como as novas condições de trabalho, vistas a partir desse cenário macro-estrutural, afetam o jornalismo, entendido como prática social, e o jornalista como agente profissional com funções específicas na sociedade.

É nesse cenário, marcado pela lógica capitalista, plenamente introduzida nas organizações, e pela emergência de variadas tecnolo-

${ }^{9}$ Emenda Constitucional $\mathrm{N}^{\mathrm{o}}$ 36 , de 28/05/2002.

${ }^{10}$ Nesse trabalho, sustentase que a flexibilização dos marcos regulatórios das comunicações, a concentração de propriedade e a monopolização dos mercados, assim como a reestruturação tecnoprodutiva das empresas, é uma contingência da racionalidade dominante no novo ciclo do capitalismo monopólico (Fonseca, 2005; 2008). 
gias de comunicação e informação que se investiga agora a forma como os valores dominantes no novo ciclo se reproduzem no jornalismo, como organização e como instituição ${ }^{11}$, razão por que se impõem as questões formuladas na abertura deste texto.

\section{Jornalismo: prática social em mudança}

O questionamento que se faz logo de início não constitui propriamente novidade na sociologia da imprensa. Max Weber já o sugeria em $1910^{12}$, restando-nos pouco mais que sua atualização. Se, no início do século XX, um dos fundadores das ciências sociais já alertava para a necessidade de se refletir sobre as implicações do aumento da demanda por capital na imprensa, com muito mais pertinência esse tipo de problema coloca-se contemporaneamente, quando o fenômeno da concentração e do monopólio atinge níveis certamente não imaginados pelo autor quando se perguntava: “[...] Nos encontramos [...] diante da criação de trusts na imprensa? [...] Quais seriam as conseqüências para o caráter dos jornais se ocorresse algo assim?" (Weber, 2005: 17).

O que se acrescenta como fator complementar à preocupação de Weber é a questão tecnologia, um dos elementos a justificar a crescente demanda por capitais, que leva as organizações jornalísticas a se lançar no mercado internacional em busca de investidores, de "parceiros" para o negócio, além de consumidores para seus produtos e serviços. Esse tipo de situação levou Jürgen Habermas, em artigo publicado na Folha de São Paulo em 2007, a comentar a possível venda do tradicional periódico alemão Süddeutsche Zeitung, motivado pela apreensão dos leitores diante da notícia de que o jornal estaria rumando para um futuro econômico de incertezas, porque a maioria dos seus acionistas decidira colocar suas ações à venda. O temor residia na possibilidade de o periódico vir "a cair na mão de investidores privados, fundos de investimento ou conglomerado de mídia" (Habermas, 2007), o que poderia conduzir sua política editorial para matérias de infotainment ${ }^{13}$, de informação e entretenimento, mais ao gosto do público, em substituição à linha argumentativa tradicional.

A objeção de Habermas a esse tipo de mudança, que se baseia na suposição de que os "consumidores" escolhem com autonomia, com base nas suas preferências pessoais, reside no fato de que essa "verdade acaciana" induz ao erro quando se trata de uma mercadoria tão peculiar quanto a informação política e cultural. "Pois essa mercadoria, a um só tempo, atende e transforma as preferências de seus consumidores" (Habermas, op. cit.).

$\mathrm{Na}$ mesma linha de raciocínio expressa pelo autor alemão, na pesquisa concluída em 2005 sugere-se a hipótese de que, para corresponder às exigências do mercado e às expectativas do leitor, em organizações multimídia totalmente subordinadas à lógica domi-

${ }^{11} \mathrm{O}$ jornalismo tomado como instituição seria o que assume determinadas funções sociais ao longo do tempo, enquanto o jornal como organização é o que materializa as funções institucionais do jornalismo em cada período histórico (Machado, 2005).

${ }^{12}$ As questões foram propostas no texto "Sociologia da Imprensa: um programa de pesquisa", em que formula um programa de pesquisa para a análise sociológica da imprensa. O texto está reproduzido na revista Estudos em Jornalismo e Mídia, vol. 2, $\mathrm{n}^{\circ} 1,2005$ (13-21).

${ }^{13}$ Fusão, em inglês, dos termos "information" e "entertainment". 
nante no atual ciclo do capitalismo, a notícia ${ }^{14}$ estaria perdendo a condição de gênero paradigmático para outras formas de conteúdo (serviço, entretenimento, fait divers). A noticiabilidade desses conteúdos oferecidos pelos jornais contemporâneos seria definida menos em função do valor-notícia "interesse público" ou importância e mais em razão de valores como "interesse do público" (gosto, preferência).

A preocupação com o tema, portanto, não se restringe à análise econômica, como poderia sugerir uma avaliação apressada, e o artigo do mais notável representante da nova geração de frankfurtianos é uma indicação disso.

Ao se problematizar esse tema, acredita-se contribuir para a ampliação da análise crítica do campo jornalístico, assim como para o debate acerca das práticas e das funções sociais dos jornalistas na estrutura social contemporânea.

\section{A identidade do jornalista contemporâneo}

Concebe-se o jornalismo como uma forma de conhecimento ${ }^{15}$, e como uma prática social integrante do processo de formação da opinião pública que, conforme Rüdiger, é dotada de conceito variável no tempo. "[...] Ligadas [as práticas] dialeticamente ao seu próprio movimento, dependem de certos regimes jornalísticos, de regras e conceitos que estruturam o jornalismo e se transformam pela práxis em curso nos diversos campos da vida social de cada época" (Rüdiger, 1993: 9). E se parte do pressuposto de que está em curso uma mudança de perfil, de valores profissionais, de identidade ${ }^{16}$ e de representação do jornalismo e do jornalista na sociedade; mudanças essas relacionadas a movimentos mais amplos de reestruturação social, condicionados pelo desenvolvimento das tecnologias e pela expansão do capital.

Como já observou Martín quanto ao papel do jornalista,

\begin{abstract}
A internet não só está mudando os modos de acesso à informação pelos utilizadores, o modelo de comunicação tradicional, a economia mundial e as empresas de comunicação, mas também o perfil do jornalista (Martín apud Aroso, 2003) ${ }^{17}$.
\end{abstract}

Nas novas ${ }^{18}$ empresas de comunicação que têm no jornalismo o seu negócio, aumenta a demanda por profissionais com novas habilidades e competências. Em razão da convergência tecnológica, que permite às empresas se constituírem como organizações multimídia, os jornalistas, regra geral, precisam ter habilidade técnica, isto é, apresentar domínio das novas tecnologias de comunicação e informação. Precisam também dominar a linguagem própria de cada meio (jornal, televisão, rádio, internet), de forma a produzir conteúdos compartilháveis entre os veículos do grupo empresarial.
${ }^{14}$ Conforme a tradição norteamericana, hegemônica na imprensa brasileira.

${ }^{15}$ Toma-se jornalismo como forma de conhecimento nos termos propostos inicialmente por Robert Park e desenvolvidos depois por vários outros autores, tais como Melo (2007), Machado (2005), Meditsch (1992) e Genro Filho (1989).

${ }^{16}$ Por identidade, entendese "o processo de construção de significado com base em um atributo cultural, ou ainda um conjunto de atributos culturais interrelacionados, o(s) qual (ais) prevalece $(\mathrm{m})$ sobre outras fontes de significado." (Castells, 2000b: 22.)

${ }^{17}$ Disponível em <http:// www.bocc.ubi.pt>. Acesso em: 25 jun. 2007.

${ }^{18}$ A expressão "novas" é tomada em sentido figurado, em função da reestruturação organizacional das empresas. 
Mas isto apenas não basta, é preciso também que conheçam e sejam capazes de implementar métodos de gestão capazes de obter o máximo de produtividade de suas equipes pelo menor custo. Do jornalista exige-se que seja também um executivo. Isso é o que se caracteriza como o período pós-fordista nas redações jornalísticas (Fonseca, 2008). Em alguns casos, como revelam programas de treinamento e qualificação, é possível que a competência técnica se sobreponha à competência profissional, relativa à identificação da informação realmente relevante para o interesse público, aos processos de apuração, à ética profissional, ao pensamento crítico, ao dever de verdade etc.

Como se pode ver, nesse ambiente, jornalismo e jornalistas transformam-se, redefinem-se, reconfiguram seus papéis sociais e assumem novas funções. Por essa razão, justifica-se discutir sua identidade.

\section{Os estudos sobre identidade}

Não são muitos, nem recentes, os trabalhos produzidos sobre o tema no âmbito dos estudos acadêmicos da Comunicação. Contudo, não sendo objeto exclusivo da área, é possível resgatar algumas discussões empreendidas também em campos afins, como a Sociologia e a Antropologia, o que confere olhar interdisciplinar à questão. Em geral, esses trabalhos procuram delinear uma identidade e/ou traçar um perfil do jornalista, à exceção do texto de Albuquerque (2004), que aborda como os programas de pós-graduação em Comunicação no país tratam o tema, discute a sua importância e faz observações quanto aos problemas teóricos e metodológicos implicados nesse tipo de investigação.

No início da última década do século passado, numa chave antropológica de leitura, visando analisar a constituição da identidade social dos jornalistas no Brasil, Travancas (1993) fez uma etnografia, acompanhando as rotinas profissionais de três repórteres (um de televisão, um de rádio e outro de jornal), e entrevistas com grupos de duas gerações de profissionais, os quais classificou de "eternos jornalistas" e "jovens jornalistas". Nessa pesquisa, a autora concluiu que a profissão tem papel central nas trajetórias de vida dos jornalistas, delimitando uma identidade particular para esses indivíduos. Segundo ela, existiria uma relação específica entre a vida pessoal e a profissão - uma verdadeira adesã $0^{21}$, que impede, muitas vezes, que outras atividades tenham maior dimensão em suas vidas. Em alguns casos essa relação seria definida, segundo a autora, como "paixão pelo trabalho", o que gera tensão, inclusive, entre outros papéis sociais - nas relações familiares e de parentesco, por exemplo.

Mais recentemente, partindo do pressuposto de que existe uma elite entre os jornalistas brasileiros, Pereira (2005) procurou iden-

${ }^{19}$ Commitment - termo do sociólogo norte-americano Howard Becker utilizado pela autora. 
tificar os profissionais circunscritos a essa condição. Para isso, valeu-se de uma enquete como método. $\mathrm{O}$ autor justificou sua pesquisa dizendo que, "à medida que um jornalista atinge o topo, sua carreira torna-se paradigmática para o grupo profissional. Todos os valores e méritos necessários ao sucesso estarão representados nesse indivíduo" 20 . As questões da enquete foram divulgadas nos sites da Universidade de Brasília, do Observatório de Imprensa, da Federação Nacional dos Jornalistas (Fenaj) e do Fórum Nacional de Professores de Jornalismo. De livre indicação, recebeu 302 votos, sendo $47 \%$ de respondentes auto-declarados jornalistas. O profissional que maior número de indicações recebeu foi Alberto Dines ${ }^{21}$. Outro dado importante obtido através da enquête ressalta a centralidade da televisão como meio que abriga a maior parte dos profissionais apontados por seus próprios colegas como constituintes da elite da profissão: dos 16 jornalistas mais votados, dez atuavam no telejornalismo.

Embora não aprofundado no artigo de Pereira (2005), o conceito de elite parece-nos permitir uma discussão produtiva sobre os valores que regem a profissão, e que contribuem, assim, para a estruturação de uma certa identidade profissional. Por essa razão, é uma alternativa teórica importante a ser considerada.

Dos estudos realizados, um dos que nos parece mais relevante para a discussão da identidade do jornalista contemporâneo é o que assume os conceitos de intelectual ideólogo e expert, formulados por Norberto Bobbio a partir de Max Weber. Esses conceitos foram operacionalizados por Abreu (1998) com a finalidade de estudar mudanças no perfil das gerações que ocupavam postos estratégicos nas redações jornalísticas brasileiras antes e depois dos anos $1970^{22}$. Com a pesquisa, a autora conclui que até essa década, os jornalistas tinham envolvimento político e ideológico claro, e agiam em função de determinados valores e utopias, o que os circunscrevia à condição de intelectuais. "Os intelectuais são aqueles que elaboram princípios que são determinados pela crença consciente nos valores, que são acolhidos como guias da ação.” (Bobbio apud Abreu, 1998: 12.)

$\mathrm{Na}$ fase posterior, a partir da introdução do marketing nas empresas, a profissão teria perdido seu caráter romântico e ideológico, e os jornalistas teriam passado a perceber sua atividade profissional como outra qualquer (engenheiro, médico, advogado, etc.). Neste caso, poderiam ser definidos como experts - aqueles que, indicando os conhecimentos mais adequados para alcançar um determinado fim, fazem com que a ação que a ele se conforma possa ser chamada de racional segundo o objetivo, distinta da ação racional segundo o valor (Bobbio apud Abreu, 1998: 12).

A definição de expert, mais do que nunca, parece-nos estar em acordo com a realidade que se observa nas redações das grandes organizações de mídia da atualidade. Um levantamento que des-

${ }^{20}$ Disponível em < www. bocc.ubi.pt> Acesso em: 13 jun 2007.

${ }^{21}$ Alberto Dines foi editorchefe do Jornal do Brasil por 12 anos e diretor da sucursal da Folha de $S$. Paulo no Rio de Janeiro e do Grupo Abril em Portugal. Atualmente coordena o observatório da imprensa na TV Brasil, na Cultura AM, de São Paulo e no site www. observatoriodaimprensa.com. br. Mais informações em: http://www.tvebrasil.com. br/observatorio/sobre_dines/ personalidade2002.htm

${ }^{22}$ Os anos 1970 são considerados como os de consolidação das indústrias culturais no Brasil (Ortiz, 1991), processo iniciado na década de 1960 com o ingresso do país na etapa monopólica do capitalismo internacional sob o controle do poder militar. 
nudasse o perfil do profissional em atuação hoje nas organizações jornalísticas, com algum grau de certeza, validaria o conceito de Bobbio, que explica sua tipologia da seguinte maneira:

Toda ação política, enquanto é ou pretende ser uma ação racional, necessita de idéias gerais a respeito dos fins a perseguir, que chamo de "princípios", mas poderia chamar também de "valores", "idealidade", "visões de mundo", e de conhecimentos científicos e técnicos necessários para alcançar os fins estabelecidos. Por "ideólogos" ${ }^{23}$, entendo os que fornecem princípios-guia, por "expertos", aqueles que fornecem conhecimentos-meio. A diferença entre um e outros pode ser interpretada mediante a distinção weberiana entre ações racionais, segundo os valores, e ações racionais, segundo os fins (Bobbio,1997: 118).

Aceitando-se, portanto, a classificação de Abreu (1998), e tomando o ponto de vista estritamente jornalístico, pode-se ainda questionar: no cenário contemporâneo em que se desenvolve a atividade jornalística (cenário sucintamente descrito no início deste texto), como se posiciona hoje o jornalista brasileiro em relação à sua própria profissão? Que papéis acredita exercer na sociedade? Atribui a si a função de vigilância, cuja missão seria a de fiscalizar, investigar e denunciar possíveis deslizes cometidos por quem detém poder, ou vê-se como mero observador, relator pretensamente objetivo e distanciado dos fatos? Ou ainda: seria mero provedor de conteúdos para distribuição nos mais diversos meios de circulação de mensagens? Esse terceiro tipo talvez possa ser percebido em alguns espaços do chamado jornalismo on-line, onde atua mais ocupado com o tempo comprimido que dispõe para disponibilizar conteúdos variados e em grande quantidade (serviços, entretenimento) que com a complexa tarefa de interpretar a realidade social.

Essas questões nos levam a acreditar que se está diante de uma identidade, por conseqüência, fragmentária, multifacetada, plural, condizente com as características do sujeito pós-moderno, como observado por Hall (2000). O caráter fragmentário certamente resulta da dualidade, às vezes atravessada por contradições, que tem origem na própria formação do jornalista ${ }^{24}$, situação agravada ao longo do tempo pelas novas demandas apresentadas pelo mercado.

A dualidade que contribui para a dificuldade de delineamento de uma identidade concebida em termos iluministas ou sociológicos ${ }^{25}$, contudo, não é específica do jornalista brasileiro contemporâneo. Analisando a realidade dos jornalistas portugueses no início do século XXI, Fidalgo observa situação semelhante:

Atravessado por ambigüidades e dualidades [...], situado numa tensão permanente entre pólos opostos que o reclamam - entre o profissional liberal de consciência e o trabalhador assalariado de facto, entre o cria-

${ }^{23}$ A tipologia corresponde, segundo o próprio autor, à distinção entre intelectuaisfilósofos e intelectuais-técnicos, introduzida por $\mathrm{G}$. P. Prandstraller (Bobbio, 1997).

${ }^{24}$ Os próprios currículos dos cursos superiores em Comunicação ou Jornalismo no Brasil são exemplo dessa dualidade entre uma formação teórica e técnica, divisão que muitas vezes separa professores "teóricos" (formação apenas acadêmica) de "práticos" (experiência no mundo do trabalho).

${ }^{25} \mathrm{O}$ sujeito do Iluminismo baseava-se numa concepção de indivíduo totalmente centrado, unificado, dotado das capacidades de razão, de consciência e de ação, cujo centro consistia num núcleo interior, que emergia e se desenvolvia com o sujeito, permanecendo o mesmo ao longo da sua existência. Já a noção de identidade do sujeito sociológico reflete a concepção de complexidade do mundo moderno e a consciência de que o núcleo desse sujeito não é autônomo nem autosuficiente, mas formado na relação com outras pessoas importantes para ele, que medeiam valores, sentidos, símbolos (cultura) que ele habita (Hall, 2000: 10-11). 
dor e o técnico, entre o intelectual e operário, entre o informador e o propagandista, entre o generalista e o especialista, entre o responsável por um autêntico serviço público e o produtor/formatador de uma simples mercadoria vendável, entre o feérico show man e o discreto mediador -, o jornalista continua este já longo caminho [...] na procura de uma melhor definição da sua especificidade, das fronteiras da sua missão própria, dos conhecimentos e competências particulares que lhe são necessários, dos meios adequados para atingir os fins que se propõe, e, enfim, de um certo bem-estar consigo mesmo e com o público a quem serve. Ou seja, uma melhor definição da sua identidade [...] (Fidalgo, 2005: 72).

A descrição do autor sobre a realidade portuguesa, assim como a nossa, sobre a brasileira, confirma o que antecipara Hall ao afirmar que o sujeito compreendido como uma identidade unificada e estável está se tornando fragmentado, composto não de uma única, mas de várias identidades, algumas vezes contraditórias ou não-resolvidas:

[...] As identidades que compunham as paisagens sociais "lá fora" e que asseguravam nossa conformidade subjetiva com as "necessidades" objetivas da cultura, estão entrando em colapso, como resultado de mudanças estruturais e institucionais. [...] Esse processo produz o sujeito pós-moderno, conceptualizado como não tendo uma identidade fixa, essencial ou permanente. A identidade torna-se uma "celebração móvel”: formada e transformada continuamente em relação às formas pelas quais somos representados ou interpelados nos sistemas culturais que nos rodeiam (Hall, 2000: 12-13).

O esforço de pensar especificidades de grupos profissionais no período que aqui nomeamos pós-fordismo ${ }^{26}$ tem de levar em conta, portanto, essa realidade por vezes desconcertante - porque inerente à lógica do capitalismo flexível e sem fronteiras da atualidade, assim como aos próprios sistemas de significação e representação cultural da pós-modernidade.

\section{Considerações finais}

A dificuldade de refletir sobre a identidade do jornalista é tema recorrente entre os pesquisadores que se dedicam ao tema. Não apenas por limitações metodológicas, que ainda precisam de melhor delineamento no campo da Comunicação, onde se desenvolve a maioria das pesquisas sobre o assunto, quanto pela dificuldade de obtenção de legitimidade entre os próprios profissionais que se encontram no mercado de trabalho ${ }^{27}$. Albuquerque (2004) advertira para o problema ao observar que pouco se desenvolveram no Brasil estudos sobre os fatores históricos e culturais que contribuem para a formação da identidade do jornalista. Além disso, sublinha o au-

${ }^{26}$ Sinônimo para regime de acumulação flexível.

${ }^{27}$ Quando se fala em mundo do trabalho dos jornalistas, neste texto, não se inclui as assessorias de imprensa, que se julga atividade de divulgação e de comunicação, mas não circunscrita ao que entendemos por jornalismo, mesmo quando desempenhada por jornalistas de formação, como ocorre no Brasil. 
tor, a análise acadêmica encontra dificuldades para legitimar o seu lugar como instância interpretativa autônoma diante dos agentes dos campos profissional e empresarial. Dito de outra forma, profissionais e empresários não reconhecem o conhecimento produzido na academia como representativo da realidade social. Ao contrário, algumas vezes procuram a universidade apenas para legitimar seus próprios pontos de vista, como através das cátedras ${ }^{28}$ ou da valorização apenas de professores com "experiência de mercado", o que contribuiria para agravar o problema.

$\mathrm{O}$ autor não condena esse tipo iniciativa, que visa influenciar o debate acadêmico, mas atenta para o seu caráter pouco satisfatório na obtenção de respostas aos problemas do jornalismo, dentre os quais a questão da identidade. A tensão do mercado com a universidade é antiga e resulta muitas vezes da incompreensão quanto ao seu papel. "O papel que cabe à perspectiva acadêmica [...] deve se fazer no sentido de ampliar o conhecimento existente [...], e isso implica necessariamente em dialogar com as interpretações correntes, tanto quanto em desafiá-las" (Albuquerque, 2004) ${ }^{29}$.

Esta é a intenção deste texto: lançar um olhar mais detido e mais informado e esclarecido pela teoria para a discussão da identidade do jornalista contemporâneo. As respostas às questões aqui formuladas, a serem buscadas através de métodos a serem ainda melhor definidos, podem constituir indícios, indicativos valiosos de novos valores compartilhados por um grupo profissional que, na sociedade, tem legitimado o poder de dizer diariamente ao público quais são os acontecimentos mais importantes do dia, reproduzindo aos pedaços, e ao mesmo tempo "construindo", a realidade social de onde extrai sua matéria-prima, a notícia.

\section{Referências}

ABREU, Alzira Alves. Jornalistas: de românticos a profissionais. In Antropolítica. Niterói: UFF, nº 5, 1998 (p. 7-19).

ALBUQUERQUE, Afonso de. A identidade jornalística no Brasil: algumas questões teóricas e metodológicas. In e-Compós (Revista eletrônica da Associação dos Programas de Pós-Graduação em Comunicação e Informação). Ed. $\mathrm{N}^{\mathrm{o}}$ 1, dez. 2004. Disponível em < http://www.compos.org.br/e-compos >. Acesso em 07/07/2008.

AROSO, Inês Mendes Moreira. A Internet e o novo papel do jornalista. Disponível em <www.bocc.ubi.pt>. Acesso em: 25 jun. 2007.

BOBBIO, Norberto. Os intelectuais e o poder: dúvidas e opções dos homens de cultura na sociedade contemporânea. São Paulo: Editora da Universidade Estadual Paulista, 1997.

CASTELLS, Manuel. A sociedade em rede. Rio de Janeiro: Paz e Terra, 2000a.

O poder da identidade. Rio de Janeiro: Paz e Terra, 2000b.

FIDALGO, Joaquim. Jornalistas: um perfil socioprofissional em mudança. 
In Comunicação e Sociedade. Vol. 5. Aveiro, 2004 (pp. 63-74).

FONSECA, Virginia Pradelina da Silveira. O jornalismo no conglomerado de mídia: reestruturação produtiva sob o capitalismo global. 2005. 349 f. Tese (Doutorado em Comunicação e Informação) - Faculdade de Biblioteconomia e Comunicação/Programa de Pós-Graduação em Comunicação e Informação, Universidade Federal do Rio Grande do Sul, Porto Alegre.

Indústria de noticias: capitalismo e novas tecnologias no jornalismo contemporâneo. Porto Alegre: Editora da UFRGS, 2008.

GENRO FILHO, Adelmo. O segredo da pirâmide: para uma teoria marxista do jornalismo. Porto Alegre: Ortiz, 1989.

HABERMAS, Jürgen. O fim do radicalismo. Folha de S. Paulo. Disponível em <http://www.uol.com.br>. Acesso em: 30 mai. 2007.

HALL, Stuart. A identidade na pós-modernidade. 4 ed. Rio de Janeiro: DP\&A, 2000.

HARVEY, David. A condição pós-moderna. 10 ed. São Paulo: Loyola, 2001.

MACHADO, Elias. O pioneirismo de Robert E. Park na pesquisa em Jornalismo. In Revista Estudos em Jornalismo e mídia: Sociologia do Jornalismo. Florianópolis: UFSC/Programa de Pós-Graduação em Jornalismo e Mídia. Vol. 2. $\mathrm{N}^{\mathrm{o}} 1$, julho de 2005 (23-33).

MEDITSCH, Eduardo. O conhecimento do jornalismo. Florianópolis: Editora da UFSC, 1992.

MELO, Isabelle Anchieta de. A notícia como forma de conhecimento segundo Robert Park. Disponível em< http://www.bocc.ubi.pt>. Acesso em: 25 jun. 2007.

ORTIZ, Renato. A moderna tradição brasileira: cultura brasileira e indústria cultural. 3 ed. São Paulo: Brasiliense, 1991.

PEREIRA, Fábio Henrique. A elite dos jornalistas brasileiros: representatividade e legitimidade dentro do grupo profissional. Disponível em < http:/www. bocc.ubi.pt > Acesso em 09/07/2008.

RÜDIGER, Francisco. Tendências do Jornalismo. Porto Alegre: Ed. UFRGS, 1993.

SODRÉ, Muniz. Eticidade, campo comunicacional e midiatização. In MORAES, Denis. Sociedade midiatizada. Rio de Janeiro: Mauad, 2006, p. 19-31.

TRAVANCAS, Isabel Siqueira. O mundo dos jornalistas. São Paulo: Summus, 1993.

WEBER, Max. Sociologia da imprensa. In Revista Estudos em Jornalismo e mídia: Sociologia do Jornalismo. Florianópolis: UFSC/Programa de Pós-Graduação em Jornalismo e Mídia. Vol. 2. Nº 1, julho de 2005 (13-21).

Receido em 21 de julho de 2008 Aprovado em 20 de outubro de 2008 